\title{
Nitric oxide system and diabetic nephropathy
}

\author{
Bruno Schmidt Dellamea ${ }^{1 *}$, Cristiane Bauermann Leitão ${ }^{1,2}$, Rogério Friedman ${ }^{1,2}$ and Luis Henrique Canani ${ }^{1,2}$
}

\begin{abstract}
About 30\% of patients with type 2 diabetes mellitus develop clinically overt nephropathy. Hyperglycemia is necessary, but not sufficient, to cause the renal damage that leads to kidney failure. Diabetic nephropathy (DN) is a multifactorial disorder that results from interaction between environmental and genetic factors. In the present article we will review the role of the nitric oxide synthase (NOS) in the pathogenesis of DN.

Nitric oxide (NO) is a short-lived gaseous lipophilic molecule produced in almost all tissues, and it has three distinct genes that encode three NOS isoforms: neuronal (nNOS), inducible (iNOS) and endothelial (eNOS).

The correct function of the endothelium depends on NO, participating in hemostasis control, vascular tone regulation, proliferation of vascular smooth muscle cells and blood pressure homeostasis, among other features. In the kidney, NO plays many different roles, including control of renal and glomerular hemodynamics. The net effect of NO in the kidney is to promote natriuresis and diuresis, along with renal adaptation to dietary salt intake.

The eNOS gene has been considered a potential candidate gene for DN susceptibility. Three polymorphisms have been extensively researched: G894T missense mutation (rs 1799983), a 27-bp repeat in intron 4, and the T786C single nucleotide polymorphism (SNP) in the promoter (rs2070744). However, the potential link between eNOS gene variants and the induction and progression of DN yielded contradictory results in the literature.

In conclusion, NOS seems to be involve in the development and progression of DN. Despite the discrepant results of many studies, the eNOS gene is also a good candidate gene for DN.
\end{abstract}

Keywords: Diabetes, Diabetic nephropathy, Polymorphism, eNOS, NOS-3, G894T, 4b/a, T786C

\section{Introduction}

About $30 \%$ of patients with type 2 diabetes mellitus develop clinically overt nephropathy [1]. Thus it appears that in humans hyperglycemia is necessary, but not sufficient, to cause the renal damage that leads to kidney failure. The risk is not linearly correlated to the duration of diabetes, with a decline after an initial progressive incidence, likely due to exhaustion of the subgroup of susceptible subjects [2,3].

Diabetic nephropathy (DN) is a multifactorial disorder that results from interaction between environmental and genetic factors. $\mathrm{DN}$ is histologically defined by thickening of the glomerular basement membrane, increased fractional mesangial volume, and podocyte abnormalities [2]. Hyperglycemia, hypertension and proteinuria are the main insults that cause structural abnormalities in a diabetic kidney [1,4-6].

The earliest known manifestation of diabetic kidney disease is the presence of small amounts of albumin in

\footnotetext{
*Correspondence: brunodellamea@gmail.com

${ }^{1}$ Universidade Federal do Rio Grande do Sul, Porto Alegre, Brazil

Full list of author information is available at the end of the article
}

the urine, known as microalbuminuria. So far it is still unknown who will evolve to end-stage renal disease, and the genetic factor is a matter for debate and further study [7].

To better understand the pathogenesis of $\mathrm{DN}$, nitric oxide (NO) must be considered, and the study of the polymorphism of genes involving it formation should be addressed.

\section{Nitric oxide system characterization}

NO is a short-lived gaseous lipophilic molecule produced in almost all tissues and organs, a free radical exerting a variety of biological actions under both physiological and pathological conditions. $\mathrm{NO}$ is a paracrine mediator formed from its precursor L-arginine by a family of NO synthases (NOSs) with stoichiometric production of L-citruline. The NO system consists of three distinct NO synthase (NOS) isoforms, encoded by three distinct genes, including neuronal (nNOS or NOS-1), inducible (iNOS or NOS-2) and endothelial (eNOS or NOS-3). The gene encoding eNOS is located on chromosome 7

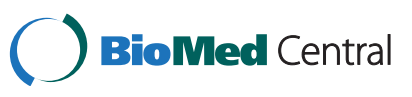


(7q35-q36) and contains 26 exons with an entire length of $21 \mathrm{~kb}$ [8-10].

\section{Nitric oxide system physiology}

eNOS expression is regulated by transcription (changes in the rate of eNOS gene transcription), stabilization (alterations in eNOS mRNA stability), and phosphorylation [11]. The presence of these consensus sites is consistent with evidence showing that levels of eNOS transcripts are elevated by sheer stress, exercise and hypoxia [12]. Regulation of eNOS transcription by estrogens is still a matter of debate. Both lipopolysaccharide and tumor necrosis factor- $\alpha$ decrease eNOS gene expression by reducing the stability of eNOS-mRNAs. The constitutively expressed eNOS-mRNA is about 4052 nucleotides long and has a half-life of 10-35 h. Therefore, synthesis of the encoded proteins is likely to persist long after gene expression has been repressed [12]. Also, the activity of eNOS and the production of $\mathrm{NO}$ are diminished in senescent human endothelial cells [13].

The endothelium is a fundamental layer in the arterial wall both for the local regulation of flow to critical organs and for the protection of the vascular system from atherogenic insults. The correct function depends on the NO generation rate [14]. NO participates in regulatory functions including control of hemostasis, fibrinolysis, platelet and leukocyte interactions with the arterial wall, vascular tone regulation, vascular smooth muscle cell proliferation and blood pressure homeostasis. Disturbances in NO bioavailability have been found to cause endothelial dysfunction, leading to increased susceptibility to atherosclerotic lesion progression, hypertension, hypercholesterolemia, diabetes mellitus, thrombosis and stroke $[15,16]$.

Insulin increases $\mathrm{NO}$ production, leading to vasodilatation and increased blood perfusion, and it also has anti-apoptotic and pro-survival effects on the ischemic/ reperfused heart. Impairment of the phosphatidylinositide 3-kinases (PI3K) - protein kinase B (AKT) - eNOS - NO pathway as a manifestation of insulin resistance contributes to endothelial dysfunction, predisposing the endothelium to hyper-inflammatory and thrombotic states, while endothelin-1 expression and mitogenic effects are not affected [17]. Exercise, diet, cardiovascular drugs and insulin sensitizers, such as angiotensin-converting enzyme inhibitors, angiotensin receptor inhibitors, and the PPARg agonists, modulate both metabolic and cardiovascular effects of insulin simultaneously by regulating PI3K-AKTeNOS signaling [18].

Data from animal models have suggested that eNOS null mice show a phenotype that resembles the human metabolic syndrome phenotype [19]. The oxidative effects of NO may play a role in insulin resistance and type 2 diabetes [20]. Two studies performed in a Spanish population found a positive association between eNOS polymorphisms and metabolic syndrome [21,22]. Another study, in an Italian population found an association with eNOS polymorphisms and insulin resistance [23]. Additionally, a positive association between G894T polymorphism and metabolic syndrome has been shown in Chinese and Japanese populations [24,25]. An association between G894TeNOS gene polymorphism and features of the metabolic syndrome was demonstrated in a southern Brazilian population, assuming a recessive model of inheritance [26].

\section{Nitric oxide system and kidney}

NO must be considered in the pathogenesis of DN, since it plays numerous physiological roles in the kidney, including control of renal and glomerular hemodynamics, by interfering at multiple and physiologically critical steps of nephron function. NO dilates both the afferent and the efferent arteriole; it may augment the glomerular filtration rate (GFR) and influence renal sodium handling along various tubule segments from the thick ascending limb to the distal tubule and the collecting duct [27]. NO is also responsible for mediation of pressure natriuresis, maintenance of medullary perfusion, blunting of tubuloglomerular reabsorption, and modulation of renal sympathetic nerve activity $[27,28]$. The net effect of NO on the kidney is to promote natriuresis and diuresis, along with renal adaptation do dietary salt intake [29,30].

High levels of nNOs are expressed in macula densa and in minor intensity in specialized neurons within renal arteries of the hilus, arcuate and interlobular arteries. eNOs is strongly expressed in renal vascular endothelium, although tubular expression of eNOS also occurs. iNOS is weakly expressed in the kidney [27]. Changes in NOS gene expression do not always correlate well with measures of actual NO synthesis, because synthesis of NO by nNOS and eNOS is highly dependent on both adequate substrate and co-factor availability [31]. Changes in requirements for $\mathrm{NO}$ synthesis in the kidney often occur very fast, so regulation of total NOS expression seems not to play an important role, and it makes it more difficult to study molecular events in the regulation of NOS in the kidney $[27,31,32]$.

The overall production of NO is decreased in chronic kidney disease (CKD), which contributes to cardiovascular events and further progression of kidney damage. There are many likely causes of NO deficiency in CKD, such as limitations on substrate (L-Arginine) availability, increased circulating levels of endogenous NOS inhibitors, in particular asymmetric dimethylarginine (ADMA). Reduced renal cortex abundance of the nNOS protein correlates with injury while increasing nNOS abundance may provide a compensatory, protective response [33].

In $\mathrm{CKD}$, ongoing endothelial damage in the capillary system of the renal medulla and accompanying vascular 
rarefaction are thought to be central processes toward progressive kidney damage [34]. Reduced NO synthesis by endothelial cells due to accumulation of inhibitors of the eNOS, such as ADMA, has been pointed out as the cause of accelerating progression. Also, erythropoietin may have vasculoprotective effects on renal endothelium, which may be critically dependent on the activation of eNOS [35].

\section{Nitric oxide system and diabetic nephropathy}

Recently, endothelial dysfunction has been commonly found in subjects with DN, and is considered the central pathophysiologic denominator for all cardiovascular complications of diabetes. In animal models of CKD and arteriosclerosis, blocking endothelial NO leads to an increase in microvascular disease, known to impair renal autoregulation [36].

Endothelial dysfunction has also been shown to lead to an uncoupling of the vascular endothelial growth factor (VEGF)-nitric oxide axis resulting in enhanced proinflammatory and proliferative effects of VEGF $[36,37]$. VEGF is increased in glomeruli and tubules in response to hyperglycemia. Whereas most studies have suggested that VEGF may be beneficial in non-diabetic renal disease, there is increasing evidence that VEGF may have a deleterious role in diabetic nephropathy. Endothelial dysfunction with NO deficiency may result in a loss of negative regulatory activity in the VEGF pathway. Consequently, VEGF may cause excessive endothelial cell proliferation, pathological macrophage infiltration, and overactivation of vascular smooth muscle cell, causing vascular injury $[38,39]$.

Endothelin-1 is inhibited by vasodilators like NO and prostacyclins. Endothelin-1 acts in the kidney rising vascular resistance, which leads to reduction in blood flux, glomerular filtration rate and inhibition of salt and water reabsorption. It also causes glomerular cellular proliferation and accumulation of extracellular matrix [17].

NOS could be involved in the development of chronic diabetes complications through others pathways, such as uncoupling protein 2 (UCP2). UCP2 is expressed in several tissues, and protects against oxidative stress, in the regulation of insulin secretion by beta cells, and in fatty acid metabolism. Moreover, UCP2 preserves endothelial function through increasing NO bioavailability secondary to the inhibition of ROS production in the endothelium [40]. UCP2 has a potential role for inflammation and apoptosis regulation. These functions have major implications for cardiovascular and cerebrovascular chronic complications of diabetes. In fact, some UCP2 polymorphisms have been associated with the presence of diabetic chronic complications [41].

The metabolic abnormalities of diabetes cause mitochondrial superoxide overproduction in endothelial cells of both large and small vessels, enhancing five major pathways to diabetic complications: polyol pathway flux, activation of protein kinase $\mathrm{C}$ isoforms, overactivity of the hexosamine pathway, increased formation of advanced glycation end products and increased expression of the receptor for advanced glycation end products [38].

A broad spectrum of findings and issues has been amassed concerning the pathophysiology of the renal NO system in diabetes. Severe diabetes with profound insulinopenia can be viewed as a state of generalized NO deficiency. Available evidence suggests that diabetes triggers mechanisms that at the same time enhance and suppress NO bioavailability in the kidney [20,42]. It has been hypothesized that during the early phases of nephropathy, the balance between these two opposing forces is shifted toward increased NO $[20,43,44]$. This plays a role in the development of characteristic hemodynamic changes and may contribute to consequent structural alterations in glomeruli. The enhanced NO production may contribute to hyperfiltration and microalbuminuria that characterizes early diabetic nephropathy [42]. Both eNOS and nNO synthase can contribute to the altered NO production, particularly the first. As the duration of exposure to the diabetic milieu increases, factors that suppress NO bioavailability eventually prevail $[20,44]$. Increasing accumulations of advanced glycation end products may be one of the culprits in this process, leading to severe proteinuria, declining renal function, and hypertension [42]. In addition, this balance is continuously modified by actual metabolic control and the degree of insulinopenia [44].

Progression of early stages of DN to end-stage kidney disease is manifested by the gradual, inexorable scarring of the renal glomerulus followed by a similar fibrosing process in the tubulointerstitial region. Diabetic glomerular fibrosis is caused by accumulation of extracellular matrix proteins in the mesangial interstitial space resulting in fibrosis manifested by either diffuse or nodular changes [45]. The use of daidzein (caveolin inhibitor), hemin (hemoxygenase activator) or NO substrate in rats significantly decreases the renal cortical collagen content as compared to diabetic rats, presenting significant improvement in BUN, serum creatinine, proteinuria, urinary output, kidney weight/ body weight, renal cortical collagen content and nitrite/nitrate levels [46,47]. Although there is some controversy, most reports suggest higher levels of NO production early in diabetes but reduced levels in progressive $\mathrm{DN}[45,48]$.

The eNOS gene has been considerate as a potential candidate gene to DN susceptibility. Over the last few years, several polymorphisms of the eNOS gene have been identified, and their association with various diseases has been explored. Three polymorphisms have been extensively subject of research in efforts to identify 
genetic predisposition to chronic diabetes mellitus microvascular complications. These polymorphisms of interest in DN are the G missense mutation (rs1799983), a 27-bp repeat in intron 4 , and the T786C single nucleotide polymorphism (SNP) in the promoter (rs2070744) [49-53]. However, not all studies support this association [54-56]. A recent meta-analysis [57], which analyzed these polymorphisms in the progression of DN, showed that G894T is significantly associated with $\mathrm{DN}$, mainly in the allele contrast genetic model. However, in this meta-analysis patients with DN were compared to healthy subjects used as controls. Therefore, one cannot be sure if the polymorphisms were associated with $\mathrm{DN}$ or diabetes mellitus itself. In another meta-analysis [58], that compared diabetic patients without nephropathy (controls) to diabetic patients with nephropathy (cases), these polymorphisms were associated with increased risk for $\mathrm{DN}$, supporting the involvement of the eNOS gene in the pathogenesis of DN.

The potential link between eNOS gene variants and the induction and progression of DN yielded contradictory results, exemplified by the association of the cited polymorphisms with ESRD and DN by some [49,51-54,59-69], but not by all studies [54-56,70]. G894T was linked to increased risk of macroalbuminuria and progression from microalbuminuria to macroalbuminuria, with declining glomerular filtration rate as serum creatinine value rises progressively, culminating in ESRD [66,67], independent of other risk factors.

These polymorphisms seem to change eNOS expression and to be associated with different levels of eNOS that make these associations clinically plausible. Intron 4 of eNOS contains a variable number of 27-pb consensus sequence repeats with the $b$ allele having five repeats and the $a$ allele having four repeats. A single nucleotide polymorphism affecting transcription of the eNOS promoter T786C reduces its activity to less than the half [71]. Plasma concentrations of NO metabolites are reduced in carriers of the "a" allele in intron 4 (intron with four repeats). The T786C SNP is strongly linked to the intron 4 polymorphism and functional studies reveal that the $\mathrm{T} 786 \mathrm{C}$ mutation reduces eNOS gene promoter activity [50].

In conclusion, NOS seems to be involved in the development and progression of DN. Despite the discrepant results of many studies, the eNOS gene is also a good candidate gene for $\mathrm{DN}$.

\footnotetext{
Abreviations

ADMA: Dimethylarginine; AKT: Protein kinase B; CKD: Chronic kidney disease; DN: Diabetic nephropathy; eNOS: Endothelial nitric oxide synthase; GFR: Glomerular filtration rate; iNOS: Inducible nitric oxide synthase; nNOS: Neuronal nitric oxide synthase; NO: Nitric oxide; NOS: Nitric oxide synthase; NOSs: Nitric oxide synthases; NOS-1: Neuronal nitric oxide; NOS-2: Induciblenitric oxide; NOS-3: Endothelialnitric oxide;
}

PI3K: Phosphatidylinositide 3-kinases; UCP2: Uncouplingprotein 2; VEGF: Vascular endothelial growth factor.

\section{Competing interests}

The author's declare that they have no competing interests.

\section{Authors' contributions}

BSD reviewed the subject, searched for studies in databases, selected articles to include in the review and wrote the manuscript. CBL participated in the search and selection of articles and helped to draft the manuscript. RF helped in selection and helped to draft the manuscript. LHC conceived of the study, participated in coordination and helped to draft the manuscript. All authors read and approved the final manuscript.

\section{Author details}

${ }^{1}$ Universidade Federal do Rio Grande do Sul, Porto Alegre, Brazil. ${ }^{2}$ Endocrine Division of Hospital de Clínicas de Porto Alegre, Porto Alegre, Brazil.

Received: 26 August 2013 Accepted: 4 February 2014

Published: 12 February 2014

\section{References}

1. Zelmanovitz T, Gerchman F, Balthazar APS, Thomazelli FCS, Matos JD, Canani LH: Diabetic nephropathy. Diabetol Metab Syndr 2009, 1(1):10.

2. Grudden G, Viberti G: Pathogenesis of Diabetic Nephropathy. In Joslin's Diabetes Mellitus. Fourteenth Editionth edition. Edited by Kahn CR. Philadelphia, PA: Lippincott Williams \& Wilkins; 2005:p. 853-866.

3. Carpena MP, Rados DV, Sortica DA, Souza BM, Reis AF, Canani LH, Crispim D: Genetics of diabetic nephropathy. Arq Bras Endocrinol Metabol 2010, 54(3):253-261.

4. Williams ME, Stanton RC: Management of Diabetic Kidney Disease. In Joslin's Diabetes Mellitus. Fourteenth Editionth edition. Edited by Kahn R. Philadelphia, PA: Lippincot Williams \& Wilkins; 2005.

5. Gross JL, Silveiro SP, Canani LH, Friedman R, Leitão CB, Azevedo MJ: [Diabetic nephropathy and cardiac disease]. Ara Bras Endocrinol Metabol 2007, 51(2):244-256.

6. Murussi MA, Coester JL, Gross SP S: Diabetic nephropathy in type 2 diabetes mellitus. Arq Bras de Endocr Metabol 2003, 47(3):207-219.

7. Murussi M, Murussi N, Campagnolo N, Silveiro SP: [Early detection of diabetic nephropathy]. Arq Bras Endocrinol Metabol 2008, 52(3):442-451.

8. Bredt DS, Snyder SH: Nitric oxide: a physiologic messenger molecule. Annu Rev Biochem 1994, 63:175-195.

9. Moncada S, Palmer RM, Higgs EA: Nitric oxide: physiology, pathophysiology, and pharmacology. Pharmacol Rev 1991, 43(2):109-142.

10. Tsutsui M, Shimokawa H, Otsuji Y, Ueta Y, Sasaguri Y, Yanagiraha N: Nitric oxide synthases and cardiovascular diseases: insights from genetically modified mice. Circ J 2009, 73(6):986-993.

11. Rippin JD, Patel A, Belyaev ND, Gill GV, Barnett AH, Bain SC: Nitric oxide synthase gene polymorphisms and diabetic nephropathy. Diabetologia 2003, 46(3):426-428.

12. Chatterjee A, Black SM, Catravas JD: Endothelial nitric oxide (NO) and its pathophysiologic regulation. Vascul Pharmacol 2008, 49(4-6):134-140.

13. Sato I, Morita I, Kaji K, Ikeda M, Nagao M, Murota S: Reduction of nitric oxide producing activity associated with in vitro aging in cultured human umbilical vein endothelial cell. Biochem Biophys Res Commun 1993, 195(2):1070-1076.

14. Vane JR, Anggard EE, Botting RM: Regulatory functions of the vascular endothelium. N Engl J Med 1990, 323(1):27-36.

15. Napoli C, Ignarro $\sqcup$ : Nitric oxide and pathogenic mechanisms involved in the development of vascular diseases. Arch Pharm Res 2009, 32(8):1103-1108.

16. Huang PL: eNOS, metabolic syndrome and cardiovascular disease. Trends Endocrinol Metab 2009, 20(6):295-302.

17. Zanatta CM, Canani LH, Silveiro SP, Burttet L, Nabinger G, Gross LL: [Endothelin system function in diabetic nephropathy]. Arq Bras Endocrinol Metabol 2008, 52(4):581-588.

18. Yu Q, Gao F, Ma XL: Insulin says NO to cardiovascular disease. Cardiovasc Res 2011, 89(3):516-524.

19. Cook S, Hugli O, Egli M, Vollenweider P, Burcelin R, Nicod P, Thorens B, Scherrer $\mathrm{U}$ : Clustering of cardiovascular risk factors mimicking the human metabolic syndrome X in eNOS null mice. Swiss Med Wkly 2003, 133(25-26):360-363. 
20. Pieper GM: Enhanced, unaltered and impaired nitric oxide-mediated endothelium-dependent relaxation in experimental diabetes mellitus: importance of disease duration. Diabetologia 1999, 42(2):204-213.

21. Gonzalez-Sanchez UL, Martinez-Larrada MT, Sáez ME, Zabena C, Martínez-Calatrava MJ, Serrano-Rios M: Endothelial nitric oxide synthase haplotypes are associated with features of metabolic syndrome. Clin Chem 2007, 53(1):91-97.

22. Fernandez ML, Ruiz R, Gonzalez MA, Ramirez-Lorca R, Couto C, Ramos A, Gutierrez-Tous R, Rivera JM, Ruiz A, Real LM, Grilo A: Association of NOS3 gene with metabolic syndrome in hypertensive patients. Thromb Haemost 2004, 92(2):413-418

23. Monti LD, Barlassina C, Citterio L, Galluccio E, Berzuini C, Setola E, Valsecchi G, Lucoti P, Pozza G, Bernardinelli L, Casari G, Piatti P: Endothelial nitric oxide synthase polymorphisms are associated with type 2 diabetes and the insulin resistance syndrome. Diabetes 2003, 52(5):1270-1275.

24. Hsieh MC, Hsiao JY, Tien KJ, Chang SJ, Lin PC, Hsu SC, Liang HT, Chen HC, Lin SR: The association of endothelial nitric oxide synthase G894T polymorphism with C-reactive protein level and metabolic syndrome in a Chinese study group. Metabolism 2008, 57(8):1125-1129.

25. Imamura A, Takahashi R, Murakami R, Kataoka H, Cheng XW, Numaguchi $Y$, Murohara T, Okumura K: The effects of endothelial nitric oxide synthase gene polymorphisms on endothelial function and metabolic risk factors in healthy subjects: the significance of plasma adiponectin levels. Eur $J$ Endocrinol 2008, 158(2):189-195.

26. Piccoli JC, Gottlieb MGV, Castro L, Bodanese LC, Manenti ERF, Bogo MR, Peres A, Rocha MIUM, Cruz IBM: Association between 894G > T endothelial nitric oxide synthase gene polymorphisms and metabolic syndrome. Arq Bras Endocrinol Metabol 2008, 52(8):1367-1373.

27. Mount PF, Power DA: Nitric oxide in the kidney: functions and regulation of synthesis. Acta Physiol (Oxf) 2006, 187(4):433-446.

28. Zoccali C: The endothelium as a target in renal diseases. J Nephrol 2007, 20(Suppl 12):S39-S44.

29. Lahera V, Salom MG, Miranda-Guardiola F, Moncada S, Romero JC: Effects of NG-nitro-L-arginine methyl ester on renal function and blood pressure. Am J Physiol 1991, 261(6 Pt 2):F1033-F1037.

30. Shultz PJ, Tolins JP: Adaptation to increased dietary salt intake in the rat. Role of endogenous nitric oxide. J Clin Invest 1993, 91(2):642-650.

31. Welch WJ, Wilcox CS: Macula densa arginine delivery and uptake in the rat regulates glomerular capillary pressure. Effects of salt intake. J Clin Invest 1997, 100(9):2235-2242.

32. Hall CN, Garthwaite J: What is the real physiological NO concentration in vivo? Nitric Oxide 2009, 21(2):92-103.

33. Baylis C: Nitric oxide deficiency in chronic kidney disease. Am J Physiol Renal Physiol 2008, 294(1):F1-F9.

34. Kang DH, Kanellis J, Hugo C, Truong L, Anderson S, Kejaschki D, Schreiner GF, Johnson RJ: Role of the microvascular endothelium in progressive renal disease. J Am Soc Nephrol 2002, 13(3):806-816.

35. Fliser D: Perspectives in renal disease progression: the endothelium as a treatment target in chronic kidney disease. J Nephrol 2010, 23(4):369-376

36. Nakagawa T, Segal M, Croker B, Johnson RJ: A breakthrough in diabetic nephropathy: the role of endothelial dysfunction. Nephrol Dial Transplant 2007, 22(10):2775-2777.

37. Valiatti FB, Crispim D, Benfica C, Valiati BB, Kramer CK, Canani LH: [The role of vascular endothelial growth factor in angiogenesis and diabetic retinopathy]. Ara Bras Endocrinol Metabol 2011, 55(2):106-113.

38. Nakagawa T: A new mouse model resembling human diabetic nephropathy: uncoupling of VEGF with eNOS as a novel pathogenic mechanism. Clin Nephrol 2009, 71(2):103-109.

39. Nakagawa T, Sato W, Glushakova O, Heinig M, Clarke T, Campbell-Thompson M, Yazuka Y, Atkinson MA, Johnson RJ, Croker B: Diabetic endothelial nitric oxide synthase knockout mice develop advanced diabetic nephropathy. J Am Soc Nephrol 2007, 18(2):539-550.

40. Tian XY, Wang WT, Xu A, Lu Y, Zhang Y, Wang L, Cheang WS, Wang Y, Yao X, Huang Y: Uncoupling protein-2 protects endothelial function in diet-induced obese mice. Circ Res 2012, 110(9):1211-1216.

41. Souza BM, Assmann TS, Kliemann LM, Gross JL, Canani LH, Crispim D: The role of uncoupling protein 2 (UCP2) on the development of type 2 diabetes mellitus and its chronic complications. Arq Bras Endocrinol Metabol 2011, 55(4):239-248.

42. Prabhakar SS: Role of nitric oxide in diabetic nephropathy. Semin Nephrol 2004, 24(4):333-344
43. Ishii N, Patel KP, Lane PH, Taylor T, Bian K, Murad F, Pollock JS, Carmines PK: Nitric oxide synthesis and oxidative stress in the renal cortex of rats with diabetes mellitus. J Am Soc Nephrol 2001, 12(8):1630-1639.

44. Komers $R$, Anderson S: Paradoxes of nitric oxide in the diabetic kidney. Am J Physiol Renal Physiol 2003, 284(6):F1121-F1137.

45. Giacco F, Brownlee M: Oxidative stress and diabetic complications. Circ Res 2010, 107(9):1058-1070.

46. Arya A, Yadav HN, Sharma PL: Involvement of vascular endothelial nitric oxide synthase in development of experimental diabetic nephropathy in rats. Mol Cell Biochem 2011, 354(1-2):57-66.

47. Katyal T, Garg A, Budhiraja RD: Combination of daidzein, hemin and bms182874 halts the progression of diabetes-induced experimental nephropathy. Endocr Metab Immune Disord Drug Targets 2013, 13(2):152-162

48. Brosius FC 3rd: New insights into the mechanisms of fibrosis and sclerosis in diabetic nephropathy. Rev Endocr Metab Disord 2008, 9(4):245-254.

49. Ksiazek P, Wojewoda P, Muc K, Buraczynska M: Endothelial nitric oxide synthase gene intron 4 polymorphism in type 2 diabetes mellitus. Mol Diagn 2003, 7(2):119-123.

50. Liu Y, Burdon KP, Langefeld CD, Beck SR, Wagenknecht LE, Rich SS, Bowden DW, Freedman BI: T-786C polymorphism of the endothelial nitric oxide synthase gene is associated with albuminuria in the diabetes heart study. J Am Soc Nephrol 2005, 16(4):1085-1090.

51. Ezzidi I, Mtiraoui N, Mohamed MBH, Mahjoub T, Kacem M, Almawi WY: Association of endothelial nitric oxide synthase Glu298Asp, 4b/a, and $-786 \mathrm{~T}>\mathrm{C}$ gene variants with diabetic nephropathy. J Diabetes Complications 2008, 22(5):331-338.

52. Buraczynska M, Ksiasek P, Zaluska W, Nowicka T, Ksiasek A: Endothelial nitric oxide synthase gene intron 4 polymorphism in patients with end-stage renal disease. Nephrol Dial Transplant 2004, 19(9):2302-2306.

53. Neugebauer $\mathrm{S}$, Baba T, Watanabe T: Association of the nitric oxide synthase gene polymorphism with an increased risk for progression to diabetic nephropathy in type 2 diabetes. Diabetes 2000, 49(3):500-503.

54. Mollsten A, Lajer M, Jorsal A, Tarnow L: The endothelial nitri oxide synthase gene and risk pf diabetic nephropathy and development of cardiovascular disease in type 1 diabetes. Mol Genet Metab 2009, 97:5.

55. Tiwari AK, Prasad P, Thelma BK, Kumar KMP, Ammini AC, Gupta A, Gupta R: Oxidative stress pathway genes and chronic renal insufficiency in Asian Indians with Type 2 diabetes. J Diabetes Complications 2009, 23(2):102-111.

56. Taniwaki H, Ishimura E, Matsumoto N, Emoto M, Inaba M, Nishizawa Y: Relations between ACE gene and ecNOS gene polymorphisms and resistive index in type 2 diabetic patients with nephropathy. Diabetes Care 2001, 24(9):1653-1660.

57. Zintzaras E, Papathanasiou AA, Stefanidis I: Endothelial nitric oxide synthase gene polymorphisms and diabetic nephropathy: a HuGE review and meta-analysis. Genet Med 2009, 11(10):695-706.

58. Zeng Z, Li L, Zhang Z, Li Y, Wei Z, Huang K, He L, Shi Y: A meta-analysis of three polymorphisms in the endothelial nitric oxide synthase gene (NOS3) and their effect on the risk of diabetic nephropathy. Hum Genet 2010, 127(4):373-381.

59. Noiri E, Satou H, Taguchi J, Brodsky SV, Nakao A, Ogawa Y, Nishijima S, Yokomizo T, Tokunaga K, Fujita T: Association of eNOS Glu298Asp polymorphism with end-stage renal disease. Hypertension 2002, 40(4):535-540.

60. Thaha M, Pranawa M, Yogiantoro, Sutjipto, Sunarjo, Tanimoto M, Gohda T, Tomino Y: Association of endothelial nitric oxide synthase Glu298Asp polymorphism with end-stage renal disease. Clin Nephrol 2008, 70(2):144-154.

61. Suzuki H, Nagase S, Kikuchi S, Wang Y, Koyama A: Association of a missense Glu298Asp mutation of the endothelial nitric oxide synthase gene with end stage renal disease. Clin Chem 2000, 46(11):1858-1860.

62. Bellini MH, Figueira MN, Piccoli MF, Marumo JT, Cendoroglo MS, Neto MC, Dalboni MA, Batista MC, Goes MA, Schor N: Association of endothelial nitric oxide synthase gene intron 4 polymorphism with end-stage renal disease. Nephrology (Carlton) 2007, 12(3):289-293.

63. Mamoulakis D, Bitsori M, Galanakis E, Vazgiourakis V, Panierakis C, Gouliemos GN: Intron 4 polymorphism of the endothelial nitric oxide synthase eNOS gene and early microangiopathy in type 1 diabetes. Int J Immunogenet 2009, 36(3):153-157.

64. Shestakova MV, Vukolova OK, Gorashko NM, Voronko OE, Balbunova NB, Nosikov W, Dedov IJ: The relationship between genetic and haemodynamic factgors in diabetic nephropathy (DN): case-control study in type 1 diabetes mellitus (T1DM). Diabetes Res Clin Pract 2006, 74:10. 
65. Zanchi A, Mozulski DK, Hanna LS, Wantman M, Warram JH, Krolewski AS: Risk of advanced diabetic nephropathy in type 1 diabetes is associated with endothelial nitric oxide synthase gene polymorphism. Kidney Int 2000, 57(2):405-413.

66. Rahimi Z, Vaisi-Raygani A, Parsian A: Concomitant presence of endothelial nitric oxide $894 \mathrm{~T}$ and angiotensin II-converting enzyme $\mathrm{D}$ alleles are associated with diabetic nephropathy in a Kurdish population from Western Iran. Nephrology (Carlton) 2012, 17(2):175-181.

67. Jafari Y, Rahimi Z, Vaisi-Raygani A, Rezael M: Interaction of eNOS polymorphism with MTHFR variants increase the risk of diabetic nephropathy and its progression in type 2 diabetes mellitus patients. Mol Cell Biochem 2011, 353(1-2):23-34.

68. Mollsten A, Vessman M, Svensson M, Forsblom C, Parkkonen M, Brismar K, Groop P, Dahiquist G: Glu298Asp and NOS4ab polymorphisms in diabetic nephropathy. Ann Med 2006, 38(7):522-528.

69. El-Din Bessa SS, Hamdy SM: Impact of nitric oxide synthase Glu298Asp polymorphism on the development of end-stage renal disease in type 2 diabetic Egyptian patients. Ren Fail 2011, 33(9):878-884.

70. Nagase S, Suzuki H, Wang Y, Kikuchi S, Hirayama A, Ueda A, Takada K, Oteki T, Obara M, Aoyagi K, Koyama A: Association of ecNOS gene polymorphisms with end stage renal diseases. Mol Cell Biochem 2003, 244(1-2):113-118

71. Asakimori YN, Yorika Y, Taniguchi T, Ito S, Ogata Y, Kyuden N, Kohno T: (-786) C polymorphism of the endothelial nitric oxide synthase gene influences the progression of renal disease. Nephron 2002, 91(4):747-751.

doi:10.1186/1758-5996-6-17

Cite this article as: Dellamea et al: Nitric oxide system and diabetic nephropathy. Diabetology \& Metabolic Syndrome 2014 6:17.

\section{Submit your next manuscript to BioMed Central and take full advantage of:}

- Convenient online submission

- Thorough peer review

- No space constraints or color figure charges

- Immediate publication on acceptance

- Inclusion in PubMed, CAS, Scopus and Google Scholar

- Research which is freely available for redistribution 